\title{
Identification of a DNA-binding site and transcriptional target for the EWS-WT1(+KTS) oncoprotein
}

\author{
Paul A. Reynolds, ${ }^{1}$ Gromoslaw A. Smolen, ${ }^{1}$ Rachel E. Palmer, ${ }^{1}$ Dennis Sgroi, ${ }^{2}$ Vijay Yajnik, ${ }^{1}$ \\ William L. Gerald, ${ }^{3}$ and Daniel A. Haber ${ }^{1,4}$ \\ ${ }^{1}$ Massachusetts General Hospital Cancer Center and Harvard Medical School, Charlestown, Massachusetts 02129, USA; \\ ${ }^{2}$ Molecular Pathology Unit, Massachusetts General Hospital, Charlestown, Massachusetts 02129, USA; ${ }^{3}$ Department \\ of Pathology, Memorial Sloan Kettering Cancer Center, New York, New York 10021, USA
}

\begin{abstract}
Desmoplastic small round cell tumor (DSRCT) is defined by a chimeric transcription factor, resulting from fusion of the N-terminal domain of the Ewing's sarcoma gene $E W S$ to the three C-terminal zinc fingers of the Wilms' tumor suppressor WT1. Although DNA-binding sites have been defined for the uninterrupted WT1 zinc finger domains, the most prevalent isoforms of both WT1 and EWS-WT1 have an insertion of three amino acids [lysine, threonine, and serine (KTS)], which abrogates binding to known consensus sequences and transactivation of known target genes. Here, we used cDNA subtractive hybridization to identify an endogenous gene, LRRC15, which is specifically up-regulated after inducible expression of EWS-WT1(+KTS) in cancer cell lines, and is expressed within primary DSRCT cells. The chimeric protein binds in vitro and in vivo to a specific element upstream of $L R R C 15$, leading to dramatic transcriptional activation. Mutagenesis studies define the optimal binding site of the (+KTS) isoform of EWS-WT1 as 5'-GGAGG(A/G)-3'. LRRC15 encodes a leucine-rich transmembrane protein, present at the leading edge of migrating cells, the expression of which in normal tissues is restricted to the invasive cytotrophoblast layer of the placenta; small interfering (siRNA)-mediated suppression of LRRC15 expression in breast cancer cells leads to abrogation of invasiveness in vitro. Together, these observations define the consequence of (KTS) insertion within WT1-derived zinc fingers, and identify a novel EWS-WT1 transcriptional target implicated in tumor invasiveness.
\end{abstract}

[Keywords: DSRCT; EWS-WT1; alternative splicing; promoter; zinc finger; invasion]

Received May 7, 2003; revised version accepted July 1, 2003.

Desmoplastic small round cell tumor (DSRCT) is a highly aggressive primitive tumor arising from the serosal surface of the abdominal peritoneum (Gerald et al. 1991; Cummings et al. 1997; Backer et al. 1998). It is characterized histologically by solid nests of small neoplastic cells expressing epithelial, muscle, and neural markers, surrounded by a dense reactive stroma. Virtually all cases have the $\mathrm{t}(11 ; 22)(\mathrm{p} 13 ; \mathrm{q} 12)$ chromosomal translocation, fusing the N-terminal domain (NTD) of EWS to zinc fingers 2-4 of WT1 (Fig. 1A; Ladanyi and Gerald 1994; Gerald et al. 1995). EWS encodes a putative RNA-binding protein (Bertolotti et al. 1998), the NTD of which mediates potent transcriptional activation when fused to a heterologous DNA-binding domain (May et al. 1993a,b; de Alava and Gerald 2000). Such chimeric transcription factors underlie a number of distinct tumors, including Ewing's sarcoma, in which the EWS NTD is fused to the DNA-binding domain of the ETS transcription factor Fli-1. In DSRCT and Ewing's sarcoma, expression of the fusion protein is driven by the ubiquitously

${ }^{4}$ Corresponding author.

E-MAIL Haber@helix.mgh.harvard.edu; FAX (617) 724-6919.

Article published online ahead of print. Article and publication date are at http://www.genesdev.org/cgi/doi/10.1101/gad.1110703. expressed EWS promoter, suggesting that specific transcriptional targets define the transformed properties in susceptible cell types.

WT1 encodes a transcription factor with four $\mathrm{C}_{2} \mathrm{H}_{2}$ zinc fingers at its $\mathrm{C}$ terminus (for review, see Lee and Haber 2001). It was initially identified based on its inactivation in the pediatric kidney cancer Wilms' tumor and subsequently was found to play an essential role in the normal differentiation of the kidney, gonads, spleen, retina, and mesothelial structures (Kreidberg et al. 1993; Herzer et al. 1999; Wagner et al. 2002). The WT1 transcript is alternatively spliced to yield a number of isoforms (Haber et al. 1993). Of particular interest is the insertion of three amino acids [lysine, threonine, and serine (KTS)] between zinc fingers 3 and 4 . The uninterrupted zinc finger domain of WT1(-KTS) binds to the 5'-GCGTGGGAGT-3' consensus sequence, leading to the transactivation of a number of target genes, including Amphiregulin, p21 ${ }^{\text {Cip } 1}$, Podocalyxin, and vitamin $D$ receptor, among others (for review, see Lee and Haber 2001). However, the far more abundant WT1(+KTS) isoform fails to bind any known DNA recognition site. A potential role for $\mathrm{WT} 1(+\mathrm{KTS})$ in pre-mRNA processing has been proposed, based on its colocalization with 
A

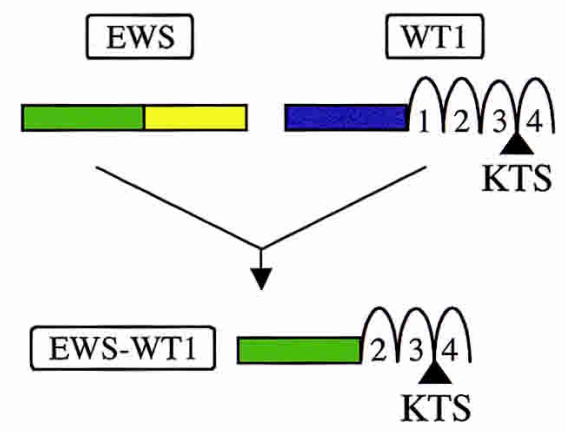

B

\begin{tabular}{c|l}
\multicolumn{2}{c}{ cDNA subtraction products } \\
\hline \# clones & \multicolumn{1}{|c}{ Gene } \\
\hline 3 & EWS-WT1(+KTS) \\
29 & LRRC15 \\
30 & Unsubtracted \\
\hline
\end{tabular}

C

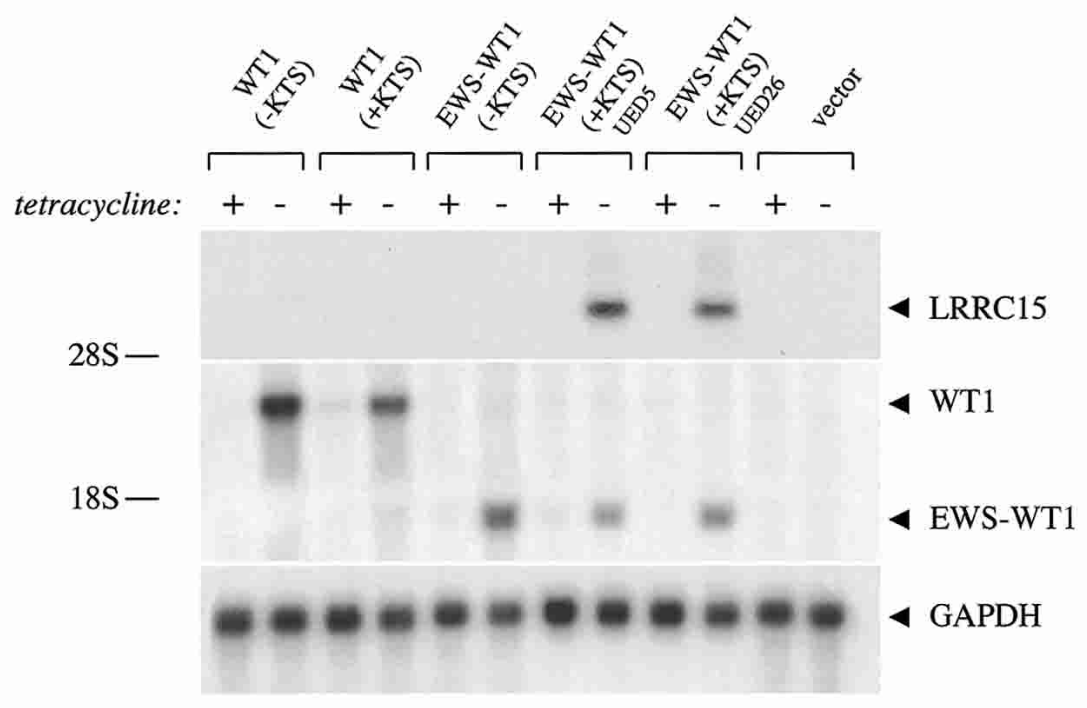

D H\&E
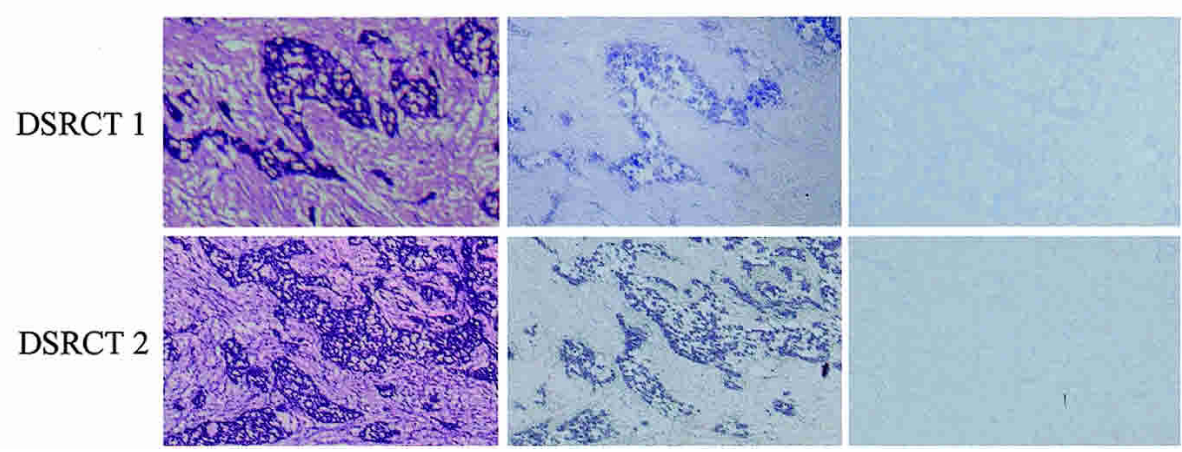

Figure 1. Induction of LRRC15 by EWS-WT1(+KTS). (A) Schematic representation of EWS, WT1, and the EWS-WT1 translocation, fusing the N-terminal domain (NTD) of EWS (exons 1-7) to the last three zinc fingers of WT1 (exons 8-10). The KTS alternative splice inserts three amino acids (lysine, threonine, and serine) between zinc fingers 3 and 4 , and is retained in the translocation product. $(B)$ cDNA subtraction results after induction of EWS-WT1(+KTS). Of 62 clones initially found to be differentially expressed upon primary hybridization screening, 32 were confirmed to be induced by Northern blot analysis. These represented only two genes: LRRC15 and EWS-WT1 itself. $(C)$ Northern blot analysis of U2OS cells demonstrating induction of endogenous LRRC15 mRNA, $12 \mathrm{~h}$ after inducible expression of EWS-WT1(+KTS), but not EWS-WT1(-KTS), WT1(+KTS), or WT1(-KTS). Blot was hybridized with probes for LRRC15, WT1 (detecting both WT1 and EWS-WT1), and GAPDH (loading control). (D) RNA in situ hybridization analysis of $L R R C 15$ in two primary DSRCT samples (magnification, 80x). Adjacent sections were stained with hematoxylin and eosin (H\&E), showing nests of tumor cells surrounded by reactive stroma. $L R R C 15$ expression is restricted to tumor cells. No staining was observed with a control (LRRC15 sense) probe. 
snRNPs within subnuclear speckles and its coimmunoprecipitation with the splicing factor U2AF65 (Larsson et al. 1995; Davies et al. 1998). Although the precise function of WT1 $1+\mathrm{KTS})$ remains to be defined, the physiological importance of this isoform is demonstrated by the developmental defects in individuals with Frasier syndrome, who have a splice junction mutation, and by the distinct abnormalities of mice engineered to lack either WT1(-KTS) or WT1(+KTS) isoforms (Barbaux et al. 1997; Klamt et al. 1998; Hammes et al. 2001).

The EWS-WT1 translocation includes zinc fingers 2-4 of WT1, preserving the alternative insertion of KTS. As for WT1, EWS-WT1 $(+\mathrm{KTS})$ is the most abundant isoform, expressed at a ratio of $\sim 2: 1$ with respect to the (-KTS) variant (Gerald et al. 1995). Studies of EWSWT1(-KTS) have demonstrated binding to the consensus sequence $5^{\prime}-(\mathrm{G} / \mathrm{C})(\mathrm{C} / \mathrm{G})(\mathrm{G} / \mathrm{C}) \mathrm{TGGGGG-3}{ }^{\prime}$, and induction of target genes, including PDGFA, IGF1R, IL2/ 15R $\beta$, and BAIAP3 (Karnieli et al. 1996; Lee et al. 1997; Finkeltov et al. 2002; Palmer et al. 2002; Wong et al. 2002). These transcripts are not induced by WT1(-KTS) itself, suggesting that the absence of WT1 zinc finger 1 in the chimera may lead to distinct DNA-binding specificity in vivo. Comparable specificity is not observed in vitro, with WT1(-KTS) and EWS-WT1(-KTS) binding to GC-rich DNA sequences and transactivating similar promoter reporters in transient transfection assays, a discordance presumably related to the importance of chromatin context. The identification of endogenous transcriptional target genes for these transcription factors is therefore critical to defining their physiological properties.

In contrast to the (-KTS) isoform, EWS-WT1(+KTS) has not been shown to bind to a specific DNA sequence or regulate gene expression. To dissect its functional properties, we undertook a cDNA subtractive hybridization, as an unbiased screen for endogenous transcripts with expression that is altered after inducible expression of this isoform. $L R R C 15$, a gene encoding a leucine-rich, transmembrane protein was found to be dramatically induced by EWS-WT1(+KTS). We used this potential EWSWT1(+KTS) target gene to demonstrate binding of EWSWT1(+KTS) to a specific DNA sequence, both in vitro and in vivo, and its ability to mediate potent transcriptional activation. A role for LRRC15 in cellular invasion is suggested by its striking expression within the cytotrophoblast cells of the placenta, which invade the maternal decidua during implantation, and by the reduced invasion of breast cancer cells after small interfering (siRNA)-mediated suppression of LRRC15 expression. EWS-WT1(+KTS) therefore encodes a transcriptional activator with a distinct DNA recognition sequence, the induction of which with $L R R C 15$ contributes to the malignant properties of DSRCT.

\section{Results}

Induction of LRRC15 by EWS-WT1(+KTS)

To identify endogenous transcripts induced by EWSWT1(+KTS), we generated U2OS osteosarcoma cells in which expression of this isoform is driven by a tetracycline-repressible promoter (UED5 cells). Poly(A)+ RNA was isolated from subconfluent cells grown in the presence of tetracycline or $12 \mathrm{~h}$ after drug withdrawal, and subjected to cDNA subtractive hybridization (PCR-select, Clontech). Differentially expressed products of 100 $\mathrm{bp}$ to $2 \mathrm{~kb}$ in size were cloned, sequenced, and used to probe Northern blots to confirm altered expression after tetracycline withdrawal. Of 32 clones validated in this screen, the EWS $-W T 1(+K T S)$ transcript itself accounted for three clones; the remaining 29 clones identified a single novel transcript (see below, Fig. 1B) that we called LRRC15 (leucine-rich repeat containing 15; Hugo Gene Nomenclature Committee-approved gene symbol, http://www.gene.ucl.ac.uk/nomenclature). Strong induction of LRRC15 is observed in two independent EWS-WT1(+KTS)-inducible cell lines (UED5 and UED26 cells), but not in cells with inducible expression of the EWS-WT1(-KTS) isoform (UF-1 cells), or with inducible constructs encoding the parental WT1|+KTS) (UD28 cells) or WT1(-KTS) (UB27 cells) isoforms (Fig. 1C). The time course of LRRC15 expression upon tetracycline withdrawal closely follows that of EWS-WT1(+KTS) itself, with earliest expression detectable at $6 \mathrm{~h}$ (data not shown). As an initial test for physiological significance, we screened primary DSRCT specimens for expression of the $L R R C 15$ transcript. In two snap-frozen primary tumor specimens with high-quality RNA, LRRC15 expression is readily evident within the characteristic nests of tumor cells, but not in the surrounding reactive stroma (Fig. 1D). LRRC15 expression was detectable by using either RNA in situ hybridization or reverse transcriptase PCR (RT-PCR) analysis in four of eight primary DSRCT specimens in which the EWS-WT1 chimera itself was successfully amplified. The reason for absence of $L R R C 15$ expression in the remaining cases is unknown and may reflect the need for additional factors regulating $L R R C 15$ expression in some DSRCTs. Thus, $L R R C 15$ was initially identified by virtue of its specific and dramatic induction by EWS-WT1 $1+$ KTS $)$ in heterologous cell lines, and found to be expressed in a subset of primary DSRCT tumors. LRRC15 expression is below detection in all normal tissues except for placenta (see below).

To clone the full-length $L R R C 15$ transcript, we generated a cDNA library from UED5 cells and performed 5' and $3^{\prime}$ RACE, combined with database analysis, yielding a 6-kb transcript with an open reading frame (ORF) of $1741 \mathrm{bp}$ and encoding a predicted protein of 581 amino acids. The gene is encoded by three exons, with the entire coding region contained within exon three. While this work was ongoing, the rat ortholog, Lib, was reported as a gene induced in rat C6 astrocyte cells upon addition of $\beta$-amyloid (Satoh et al. 2002). LRRC15 is a member of the leucine-rich repeat (LRR) superfamily, encoding transmembrane proteins thought to function in a broad array of cell-cell interactions (Kobe and Deisenhofer 1994, 1995). Of note, two close homologs are colocated in tandem with LRRC15 at 3q29: GP5 (GenBank accession no. Z23091) and CPN2 (GenBank accession no. 
J05158) share $45 \%$ and $44 \%$ overall amino acid identity, respectively, as well as a similar genomic structure, consistent with a genomic duplication event (Fig. 3A, below). Of note, only $L R R C 15$ is induced after expression of EWS-WT1 $(+\mathrm{KTS})$ (data not shown).

As predicted by its amino acid composition, LRRC15 encodes a protein localized to the plasma membrane. Notably, expression of epitope-tagged LRRC15 in HT1080 cells demonstrates colocalization with F-actin at the leading edge of migrating cells (Fig. 2B). Initial biochemical characterization also demonstrates LRRC15 to be a glycoprotein. The transfected protein migrates at $\sim 100$ $\mathrm{kD}$, with progressive reduction in apparent size after digestion of lysates with PNGase F (removing N-linked sugars) and sialidase A, endo-O-glycosidase, $\beta(1-4)$ galactosidase, and glucosaminidase (removing O-linked sugars). The deglycosylated protein migrates closer to the predicted size of $64 \mathrm{kD}$ (Fig. 2C).

\section{Transcriptional activation of LRRC15} by EWS-WT1(+KTS)

To determine whether $L R R C 15$ constitutes a direct transcriptional target of EWS-WT1(+KTS), we first tested its potential regulatory sequences for responsiveness by using promoter reporter constructs. However, luciferase constructs containing $2.5 \mathrm{~kb}$ of genomic sequence upstream of the transcriptional start site failed to show induction after cotransfection with EWS-WT1|+KTS), as did the entire sequence of introns 1 and 2. To search for more distant regulatory sequences, we isolated a BAC centered around LRRC15 and spanning $120 \mathrm{~kb}$ of genomic sequence (573k19). After EcoRI, BglII, or HindIII restriction, fragments of the BAC were cloned into the promoter-less luciferase reporter plasmid pGL3 to generate a library, which was then screened in pools for responsiveness to EWS-WT1(+KTS) in U2OS cells. An initial pool of eight clones (H6) demonstrated a mean of approximately sevenfold activation after cotransfection with CMV-driven EWS-WT1 $1+$ KTS) (background less than threefold; Fig. 3B). Individual clone HC6 demonstrated 13 -fold activation by EWS-WT1(+KTS), with further subcloning to generate HC62 (35-fold activation), and finally HC63, a minimal 142-bp region within HC62 with 50-fold transcriptional activation. Mapping of this sequence (AC108676: nucleotides 75,838-75,979) within the genomic contig showed it to be $70 \mathrm{~kb}$ upstream of the LRRC15 transcriptional start site (AC125362: nucleotide 33,964).

The (+KTS) isoforms of both WT1 and EWS-WT1 have not been shown to bind to a specific DNA sequence. To determine whether transcriptional activation of the HC63 element results from direct DNA binding by EWS-WT1(+KTS), we first tested in vitro binding by using electrophoretic mobility shift assays (EMSAs) and bacterially synthesized DNA-binding domains of the chimera or parental WT1 (Fig. 3C). Binding to HC63 is restricted to the $(+\mathrm{KTS})$ isoform of EWS-WT1, with a minimal gel shift observed after incubation with the (-KTS) variant. The parental WT1|+KTS) DNA-binding domain (including zinc finger 1) does not bind to HC63. Binding by the (+KTS) isoform of EWS-WT1 is specifically competed with a molar excess of unlabeled probe, and supershifting of protein-DNA complexes was achieved by using antibodies against the WT1 domain of the chimera, but not with nonspecific antibodies (Fig. 3C). Of note, two gel shifted bands are observed after incubation of EWS-WT1(+KTS) with HC63, consistent with the presence of two binding sites (see below).

To confirm that EWS-WT1 $(+\mathrm{KTS})$ binds to HC63 in vivo, we used chromatin immunoprecipitation (ChIP) to enrich for DNA fragments bound by the chimera. UED5 cells were grown in the absence of tetracycline and treated with formaldehyde, and cross-linked proteinDNA complexes were immunoprecipitated by using antibodies against either the WT1 zinc finger domain (C19) or the C-terminal HA-epitope tag $(\alpha \mathrm{HA})$. Selective enrichment of the HC63 sequence is observed using both antibodies, relative to control ( $\beta$-actin) sequences (Fig. 3D). No enrichment is observed in the absence of antibody or in mock immunoprecipitated samples (rabbit preimmune serum), nor is there enrichment of HC63 template from U2OS cells with induced expression of EWS-WT1(-KTS). We also examined an unrelated site (AC125362: 47844-48021) within the BAC but outside HC6, demonstrating no enrichment with this template (data not shown). Thus, EWS-WT1 $1+$ KTS) encodes a DNA-binding protein that binds in vitro and in vivo to a specific DNA sequence, mediating transcriptional activation. HC63 is located at some distance from the LRRC15 transcriptional start, suggesting that regulation of gene expression may involve chromatin looping, as shown recently for regulation of the $\beta$-globin gene by its HS2 enhancer (Carter et al. 2002).

\section{Definition of EWS-WT1(+KTS) binding consensus sequence}

To define the precise binding sequence for EWSWT1(+KTS), EMSA was performed by using overlapping, radiolabeled double-stranded probes spanning HC63 (Fig. 4A). Two binding sites were identified: the first between nucleotides 41 and 70 (HC63-1), and the second between nucleotides 81 and 110 (HC63-2). Extensive in vitro mutagenesis of HC63-1, combined with EMSA, identified six essential residues: E(KTS)RE1 (HC63 nucleotides 5560; Fig. 4B). Substitution of $G_{1}, G_{2}, G_{4}$, and $G_{5}$ to adenine or substitution of $\mathrm{A}_{3}$ to thymine results in complete or significant loss of binding. Analysis of HC63-2 identified a very closely related sequence required for DNA binding: E(KTS)RE2 (HC63 nucleotides 91-96; Fig. 4C). The two sequences differ only at position 6 (Fig. 4E). Substitution of $A_{6}$ to thymine in E(KTS)RE1 results in loss of binding (Fig. 4B), whereas substitution of $\mathrm{G}_{6}$ to adenine in $\mathrm{E}(\mathrm{KTS}) \mathrm{RE} 2$ has a minimal effect (Fig. 4C). Hence, position 6 is required for DNA binding, with $\mathrm{A}_{6}$ interchangeable with $\mathrm{G}_{6}$. On either side of the 6-bp sequence, substitution of $\mathrm{G}(-1)$ or $\mathrm{T}(+1)$ has a minimal effect on DNA binding. The effect of mutations in the binding site was confirmed by using EMSA competition assays. In- 
Reynolds et al.

corporation of $\mathrm{G}_{2} \mathrm{~A}$ into an unlabeled oligonucleotide prevents competition for binding to radiolabeled HC632, whereas $\mathrm{G}_{6} \mathrm{~A}$ competes effectively (Fig. 4D). Taken together, these experiments suggest a novel recognition consensus sequence for EWS-WT1 $(+\mathrm{KTS})$ : 5'-GGAG G(A/G)-3' (Fig. 4E).

A

KLRRC 15 ILRRC15 IILRRC15 GP5

hLRRC15 ILRRC15 ILRRRC15 GP5

hLRRC15 ILRRC15 MLRRC15 GP5

hLRRC15 ILRRC15 MLRRC15 GP5

hLRRC1 5 ILRRC15 MLRRC15 GP5

hLRRC15 ILRRC15 mLRRC15 GP5

hLRRC15 ILRRC15 MLRRC
GP5

hLRRC 15 ILRRC15 MLRRC 15 GP5
1 MPIKHYLLLLVGCQAWGAGLAYHGCPSECTCSRASQVECTGARIVAVPTPLPWNAMSLQILNTHITELNESPFLNISALI 1 MPLKHYLLLLVGCQAWALGLAYYGCPSECTCSRASQVECTGARIVAMPTPLPWNAMSLQVVNTHITELPENLFLNISALI MPLKHYLLLLVSCQAWAAGLAYYGCPSECTCSRASQVECTGAQIVAMPSPLPWNAMSLQILNTHITELPEDKFLNISALI 1 ---MLRGTLLCAVLGLLRAQPFPCPPACKCVFRDAAQCSGGDVARI SALGLPTNLTH ILL FGMGRGVLQQSFSGMTVLQ (1) MLRGLLALLRA

81 ALRTEKNEISRTTPGAFRNLGSLRYLSLANNKLOVLPIGLFOGLDSIESILLSSNOLLOIOPAHESOCSNLKELOLHGNH 81 AI 81 ATKMEKNEI 77 RLMISDSHISAVAPGTFS DIIKIKTLRLSRNKITHLPGALIDKMVLLEQIFLDHNALRGIQN-MFQKLVNLQEIALNQNQ

161 LEYIPDGAFDHIVGLTKINLGKNSITHISPRVFQHLGNLQVLRLYENRITDIPMGTEDGLVNLQELALQQNQIGLLSPGL 161 LESIPEEAFDHLVGLTKLNLGRNSFTHLSPRLFQHLGNLQVLRLHENRLSDIPMGT FDALGNLQELALQENQIGTLSPGI 161 LEYIPEGVFDHLVGLTKLNLGNNGFTHLSPRVEQHLGNLQVLRIYENRISDI PMGT FDALGNLQELALQENQIGTLSPGL 156 LDFLPASLFTNLENLKLLDLSGNNLTHLPKGLLGAQAKLERLLLHSNRLS-IDSGILNSLGALTELQFHRNHIRSIAPGA
$\square$

241 FHNNHNLORLYLSNNHISOLPPS IFMOLPOLNRLTLFGNSLKELSLG IFGPMPNLRELWLYDNHISSLPDNVESNIRQLQ

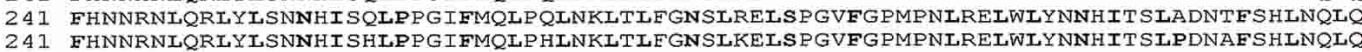
241 FHNNRNLQRLYISNNHISHIPPGIFMQLPHLNKLTLFGNSLKELSPGVFGPMPNLRELWLYNNHITSILDNAFSHLNQLQ
235 FDRLPNLSSLTISRNHLAFLPSALFLHSHNLTLLTLFEN-PAELPGVLFGEMGGLQELWLNRTQIRTLPAAAFRNLSRIR

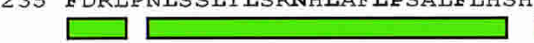

321 VIILSRN-QISFISPGAFNGLTELRELSLHTNAIQDLDGNVFRMLANLQNISLQNNRLRQLPGNIFANVNGLMAIQLQNN 321 VIILSHN-QLTYISPGAFNGLTNLREISIHTNAIQDLDSNVFRSLANLQNISLQSNRLRQLPGS IFANVNGLTTIQLQNN 321 VIILSHN-QLSYISPGAFNGLTNLRELSLHTNALODLDGNVERSLANLRNVSLONNRLRQLPGS I FANVNGLMTIOLONN 314 YLGVTLSPRLSALPQGAFQGLG--ELVLALSNGLTALPDGLLRGLGKLRQVSLRRNRLRALPRAIFRNLSSLESVQLDHN

\section{-}

400 QLENLPLGIFDHLGKLCELRLYDNPWRCDSDILPLRNWLLINQPRLGTDTVPVCFSPANVRGQSIIIIN-VNVAVPSVHV 400 NLENLPLGIFDHLVNLCELRLYDNPWRCDSDILPLHNWLLLNRARLGTDTLPVCSSPANVRGQSIVIIN-INEPGPSVQG 400 NLENLPLGIFDHLGNLCELRLYDNPWRCDSNILPLHDWLIINRARLGTDTLPVCSSPASVRGQSIVIIN-VNEPGPSVQG 392 QLETLPGDVFGALPRITELIGHN-SWRCDCGLGPELGWLRQHLGLVGGEEPPRCAGPGAHAGLPLWALPGGDAECPGPRG

\section{$\square$}

479 PEVPSYPETPWYPDTPSYPDTTSVSSTTELT-SPVEDYTDLTTIQVTDDRSVWGMTQAQSGLAIAAIVIGIVALACSLAA 479 PETP---EVPSYPDTPSYPDTTSVSSTTEIT-SAVDDYTDITTTEATDDRNTWGMTEAOSGIATAATVIGIIAIACSLAA 479 PETP---EVSSYPDTSSYPDSTSISSTTEITRSTDDDYTDLNTIEPIDDRNTWGMTDAQSGLAIAAIVIGIIALACSLAA 471 PPPPAADSSSEAPVHPALAPNSSEPWVWAQP-----VTTGKGQDHSPFWGFYFLILAVQAMITVIIVFAMIK----

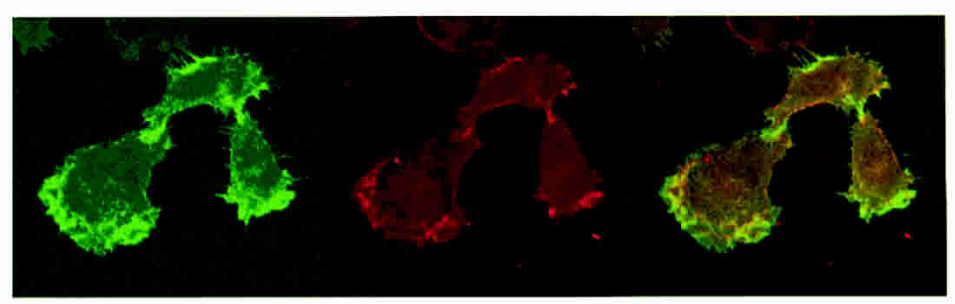

\section{HA-LRRC15 F-actin Merge}

C

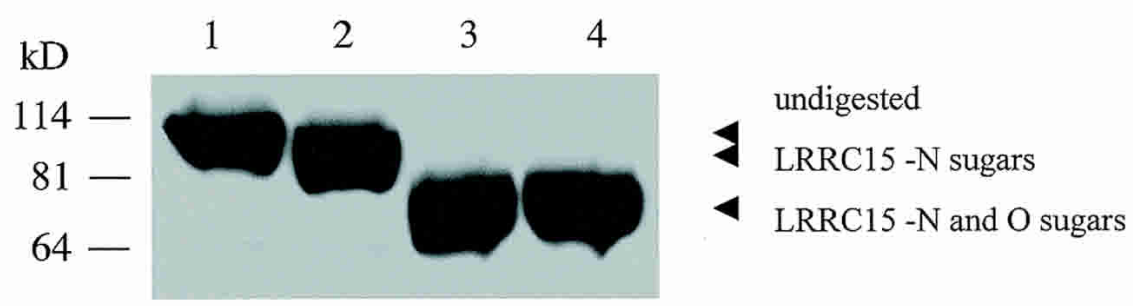

anti-HA

(Figure 2 legend on facing page.) 
To test whether the E(KTS)RE1 and E(KTS)RE2 sequences are indeed responsible for the transactivation of HC63 by EWS-WT1(+KTS), we disrupted these sequences, either alone or in combination, within the fulllength HC63-reporter (Fig. 4F). Triple substitutions of $G_{1}, G_{2}$, and $G_{4}$ to adenine were made within both $\mathrm{E}$ (KTS)RE1 and E(KTS)RE2. Wild-type or mutant reporters were cotransfected along with CMV-driven EWSWT1(+KTS) into U2OS cells. Disruption of E(KTS)RE1 alone greatly reduces EWS-WT1(+KTS)-mediated transactivation of HC63, whereas disruption of both binding sites essentially abrogates EWS-WT1(+KTS)-dependent transactivation of HC63 (Fig. 4G). Thus, two sequences, $\mathrm{E}(\mathrm{KTS}) \mathrm{RE} 1$ and E(KTS)RE2, are responsible for activation of this responsive element by EWS-WT1(+KTS).

The discovery of a specific DNA-binding sequence for EWS-WT1(+KTS) has implications for the functional properties of the parental WT1(+KTS) protein, which includes an additional $\mathrm{N}$-terminal zinc finger. To gain insight into the binding properties conferred by addition or omission of WT1-derived zinc fingers, we tested combinations of these for binding to HC63-1 (Fig. 5). Among the zinc fingers present in the chimera [2-3(KTS)-4], zinc finger 2 is essential for binding, because the 3-(KTS)-4 combination is unable to bind HC63-1. Surprisingly, fingers 2 and 3 consistently demonstrate increased in vitro binding, compared with 2-3-(KTS)-4. The reduction in in vitro binding associated with the presence of (KTS)-4 may be compensated by additional specificity in vivo (see below). By analogy with the crystal structure of the related EGR1 protein (Pavletich and Pabo 1991), the KTS insertion places the fourth zinc finger out of register with respect to the major groove of DNA. When the fourth zinc finger is in phase, as in 2-3-4, binding to HC63-1 is greatly reduced. Similarly, presence of zinc finger 1, in both 1-2-3-(KTS)-4 and 1-2-3, prevents recognition of the E(KTS)RE sites. Taken together, these observations suggest that zinc fingers 2 and 3 are required for optimal binding of the E(KTS)RE consensus. Zinc finger 4 may modulate binding when placed out of phase by the KTS insertion, but the presence of either zinc fingers 1 or 4 within the major groove abolishes binding by the adjacent fingers 2 and 3 .

\section{Contribution of LRRC15 to cellular invasion}

Identification of $L R R C 15$ as the only transcript induced after EWS-WT1(+KTS) expression in our cDNA subtraction assay raised the possibility that its functional prop- erties may contribute to transformation by the chimera. Like other EWS-dependent translocation products, tumorigenicity assays have not been well defined for EWSWT1, with only the (-KTS) isoform mediating a modest transforming effect in NIH3T3 cells (Kim et al. 1998). Cell type-specific oncogenic effects have been postulated, but the cell of origin for either Ewing's sarcoma or DSRCT remains to be defined. To gain insight into the functional properties of LRRC15, we therefore first searched for normal tissues demonstrating physiological expression of this gene. Consistent with previous studies of the rat ortholog Lib (Satoh et al. 2002), Northern blot analysis demonstrated $L R R C 15$ expression only in placenta (data not shown). To define the specific cell type expressing $L R R C 15$, we undertook RNA in situ hybridization experiments by using sections of mouse placenta. Remarkably, Lrrc15 expression is restricted to the cytotrophoblast cell layer (Fig. 6A). These cells constitute the invasive layer of the placenta, which invades the maternal decidua during implantation of the embryo (Morrish et al. 1998).

The unique physiological expression pattern of $L R R C 15$ suggested a potential role in cellular invasion. Expression of $L R R C 15$ in established human cancer-derived cell lines is uncommon, but we identified high levels of expression in Hs467T breast carcinoma cells by Northern blotting (data not shown). These cells are highly invasive, penetrating matrigel-coated pores to an extent comparable to that of the HT1080 fibrosarcoma cell line commonly used to calibrate such assays (Albini et al. 1987; Kobayashi et al. 1992). Treatment of Hs467T cells with siRNA specific to $L R R C 15$ successfully reduced levels of the endogenous transcript (Fig. 6B). Invasion of LRRC15-knockdown cells through matrigel was reduced by $65 \%$, whereas cells treated with a nonspecific siRNA showed no change (Fig. 6B). As a control, migration of Hs467T cells through uncoated plastic pores, an index of cellular motility rather than invasion, was not altered by reduction of $L R R C 15$ expression. These observations suggest that LRRC15 induction by EWSWT1(+KTS) contributes to the invasive phenotype of DSRCT.

\section{Discussion}

We have used cells with inducible expression of EWS$\mathrm{WT} 1(+\mathrm{KTS})$ and subtractive cDNA hybridization to identify the first transcriptional target for a $(+\mathrm{KTS})$ isoform of the Wilms' tumor-derived zinc fingers. The dem-

Figure 2. Structure and expression of LRRC15. (A) Sequence alignments of LRRC15 protein from human, rat, and mouse and of the related human GP5, using the ClustalW program. Domains of LRRC15 are underlined with colored bars: A signal peptide (red) is followed by a characteristic leucine-rich repeat (LRR) N-terminal flanking domain (yellow), 15 LRRs (green), a C-terminal flanking domain (yellow), one transmembrane domain (blue), and a short cytoplasmic domain. Within each LRR, a number of positions are highly conserved (bold). (B) Localization of HA-tagged LRRC15 in HT1080 cells. Cells were grown on vitronectin-coated slides and stained with antibody against the HA-epitope (green). Phalloidin staining marks the distribution of F-actin (red) with regions of overlap at the leading edge of migrating cells evident on the merged image (yellow). (C) Western blot analysis of cellular extracts from HT1080 cells expressing HA-tagged LRRC15. Denatured protein (lane 1) was incubated with PNGase F (lane 2); or PNGase F, Sialidase A, and endo-O-glycosidase (lane 3); or PNGase F, Sialidase A and endo-O-glycosidase, $\beta(1-4)$ galactosidase, and glucosaminidase (lane 4). 
Reynolds et al.

A

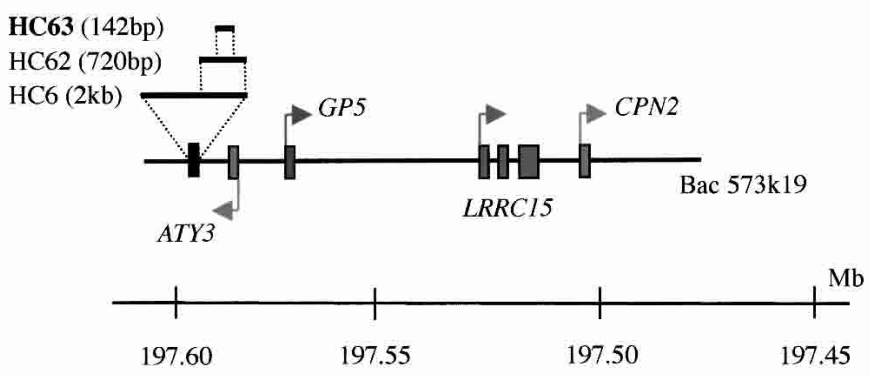

B

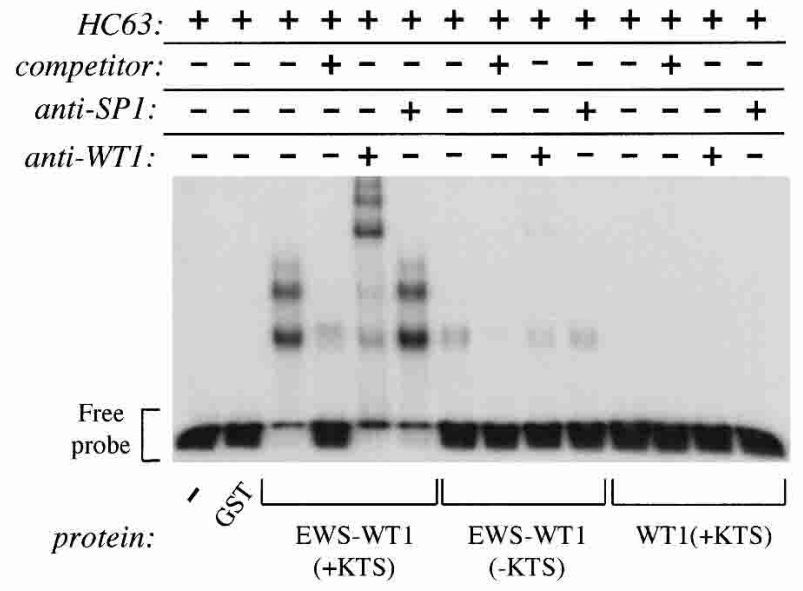

C

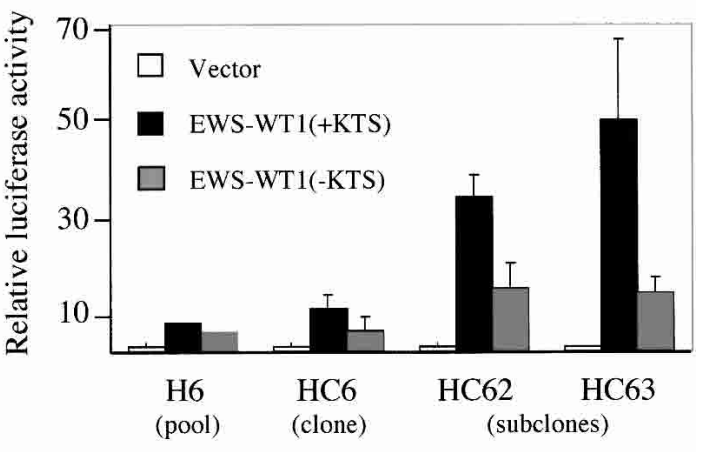

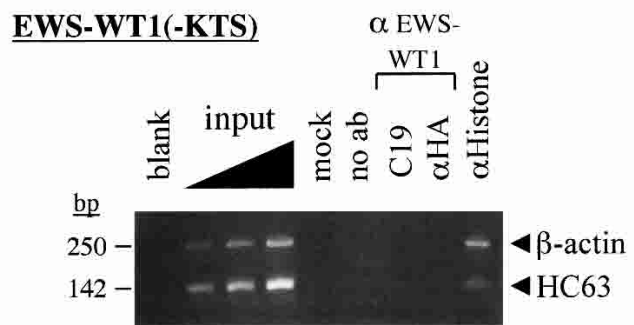

Figure 3. Identification of EWS-WT1(+KTS) responsive element. (A) Schematic representation of the LRRC15 locus (current release of http://genome.ucsc.edu and release 12.31.1 of http://www.ensembl.org). The location of the HC63 fragment, the transcriptional start site of $L R R C 15$, and neighboring genes (GP5, GenBank accession no. Z23091; CPN2, GenBank accession no. J05158; and ATY3, GenBank accession no. AJ306929) are shown. (B) Activation of LRRC15 upstream sequences by EWS-WT1(+KTS). Luciferase activity, relative to vector-transfected cells, was measured in U2OS cells, $48 \mathrm{~h}$ after cotransfection of reporter constructs $(0.2 \mu \mathrm{g})$ and either EWS-WT1(+KTS) or EWS-WT1(-KTS) expression plasmids (1 $\mu \mathrm{g})$. H6 denotes the pool of eight HindIII-digested fragments derived from BAC 573k19, which consistently showed transactivation by EWS-WT1(+KTS) (out of 36 pools tested); HC6 is the individual clone (2-kb HindIII fragment; AC108676, 74101-76107) within the pool that was found to be induced by EWS-WT1(+KTS); HC62 is a 720-bp BgIII/HindIII digest fragment from HC6 (AC108676, 75379-76107); HC63 is a 142-bp fragment of HC62. Transfection efficiency was standardized by using a cotransfected reporter (Renilla luciferase), and equal amounts of CMV promoter were present in each transfection. Standard deviations were derived from three independent experiments. $(C)$ EMSA analysis of HC63 after incubation with the zinc finger domains of EWS-WT1(+KTS), EWS-WT1(-KTS), or WT1 $(+$ KTS). End-labeled probes were incubated with 200 ng of the respective GST fusion protein or GST alone. Addition of unlabeled probe at 100-fold molar excess is shown to demonstrate competitive binding. Supershifting of the protein-DNA complex is shown by using anti-WT1 antibody (C19) or a control antibody (Sp1). Migration of free probe is shown (brackets). (D) Chromatin immunoprecipitation (ChIP) analysis to demonstrate in vivo binding of EWS WT1(+KTS) to HC63. Chromatin was extracted from U2OS cells with tetracycline-regulated expression of either EWS-WT1(+KTS) (top) or EWS-WT1(-KTS) (bottom) after growth in the absence (12 h) of tetracycline; was formaldehyde cross-linked; and was immunoprecipitated by using antibody C19 (directed against the WT1 zinc finger domain), anti-HA (against the HA epitope), anti-histone H3 antibody (positive control), rabbit preimmune serum (mock), or no antibody. Multiplex PCR was performed by using primers specific for HC63 together with $\beta$-actin (internal standard); progressive dilutions of total chromatin were also amplified to demonstrate the linearity of multiplex PCR amplification (input).

onstration of direct in vivo binding of EWS-WT1 $(+\mathrm{KTS})$ to a specific DNA recognition site has implications for understanding the functional properties of the $(+\mathrm{KTS})$ variants. The properties of LRRC15 itself provide additional insight into the mechanisms by which the EWS-
WT1 translocation drives malignant transformation in DSRCT.

The $\mathrm{C}_{2} \mathrm{H}_{2}$ zinc finger transcription factor family represents the most common class of DNA-binding motifs found in eukaryotes (Lander et al. 2001; Tupler et al. 
A

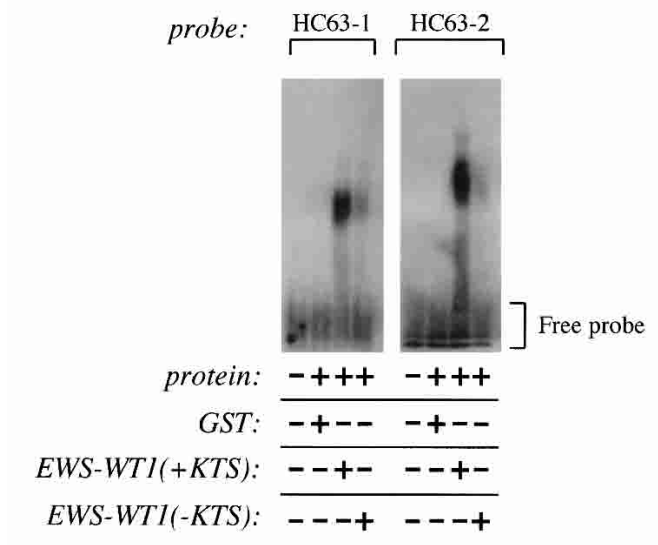

B
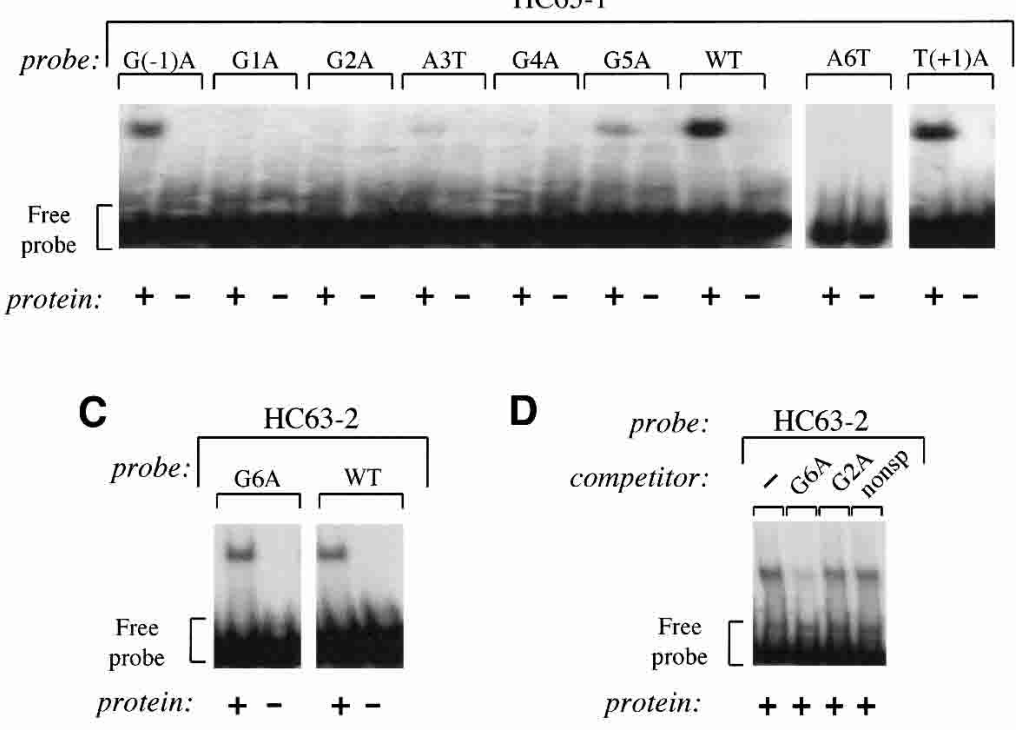

D

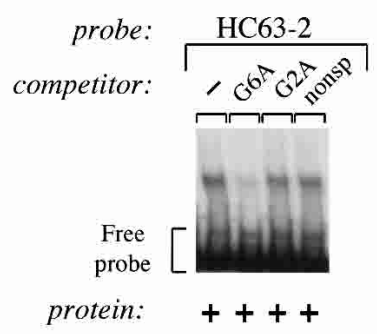

E

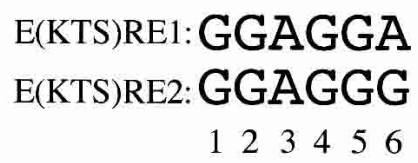

$\mathbf{F}$

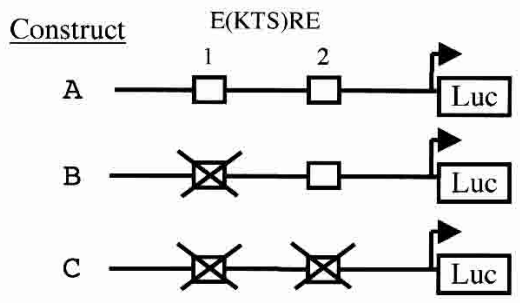

G

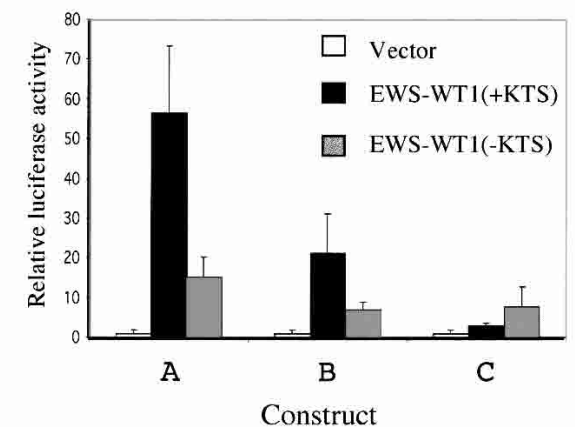

Figure 4. Characterization of EWS-WT1 $(+\mathrm{KTS})$ responsive element E(KTS)RE. (A) EMSA analysis of two fragments within HC63 that demonstrate binding by EWS-WT1(+KTS): HC63-1 (30 bp) and HC63-2 (30 bp). End-labeled probes were incubated with $200 \mathrm{ng}$ of the zinc finger domains of EWS-WT1(+KTS), EWS-WT1(-KTS), or GST alone. Migration of free probe is shown (brackets). The two panels are derived from the same gel. (B) Identification of essential residues for EWS-WT1(+KTS) binding within HC63-1. EMSA of EWSWT1 $(+$ KTS $)$ protein $(+)$ versus free probe $(-)$ is compared by using probes containing a substitution at each nucleotide that constitute the 6-bp minimal binding domain, which we call E(KTS)RE-1. All nonadenine bases were changed to adenine; adenine bases were changed to thymine and compared with binding to wild-type sequence (WT). Numerical positions correspond to the E(KTS)RE sequence. Equal amounts of probe and protein were added in all cases. Migration of free probe is shown (brackets). The two panels are derived from the same gel. $(C)$ Comparable binding of EWS-WT1 $(+\mathrm{KTS})$ to $\mathrm{E}(\mathrm{KTS}) \mathrm{RE}$ containing either a guanine or adenine at position 6. This nucleotide is the only divergence between the binding sequence identified in fragment HC63-1 and HC63-2. EMSA lanes derived from the same gel are shown, with equal amounts of probe and protein $(+)$ added in all cases. $(D)$ Competition of unlabeled oligonucleotide with the guanine-to-adenine substitution at E(KTS)RE position 6 for binding to end-labeled HC63-2 (100-fold excess competitor). In contrast, the $\mathrm{G}_{2} \mathrm{~A}$ substitution fails to compete in EMSA, as does a nonspecific oligonucleotide derived from HC63 (nonsp). (E) Minimal binding sequence for EWS-WT1(+KTS). The sequences derived independently from HC63-1 [E(KTS|RE1] and HC63-2 [E(KTS|RE2] are shown. These sites differ at position 6, where equivalent binding is observed with either adenine or guanine, but not with thymine. The E(KTS)RE sequence does not constitute a subset of the DNA-binding consensus derived for the related zinc fingers of WT1(-KTS) (WTE, 5'-GCGTGGGAG-3') or EWS-WT1(-KTS) [E-WRE, 5'-(G/C)(C/G)(G/C)TGGGGG-3']. (F) Schematic representation of the promoter-less pGL3 basic reporter, containing the two $\mathrm{E}(\mathrm{KTS}) \mathrm{RE}$ binding sites within HC63 (construct A). Triple substitutions of $\mathrm{G}_{1}, \mathrm{G}_{2}, \mathrm{G}_{4}$ to A were engineered in $\mathrm{E}(\mathrm{KTS}) \mathrm{RE} 1$ (construct $\mathrm{B}$ ), or in both $\mathrm{E}(\mathrm{KTS}) \mathrm{RE} 1$ and $\mathrm{E}(\mathrm{KTS}) \mathrm{RE} 2$ (construct C). (G) Relative luciferase activity, $48 \mathrm{~h}$ after transfection of mutant reporter constructs A through C $(0.2 \mu g)$, along with EWS-WT1(+KTS), EWS-WT1(-KTS), or vector $(1 \mu \mathrm{g})$, into U2OS cells. Transfection efficiency was standardized by using a cotransfected reporter (Renilla luciferase), and equal amounts of CMV promoter were present in each transfection. Standard deviations were derived from three independent experiments.

2001; Venter et al. 2001; Waterston et al. 2002). Many zinc fingers are thought to recognize a 3-4-bp DNA sequence, although some may also be involved in RNA or protein interactions. Structural studies of the Zif268/
EGR1 binding domain, which is closely related to zinc fingers 2, 3, and 4 of WT1, indicate that it is wrapped around DNA, with each zinc finger residing within the major groove (Pavletich and Pabo 1991). However, in- 
Reynolds et al.

A

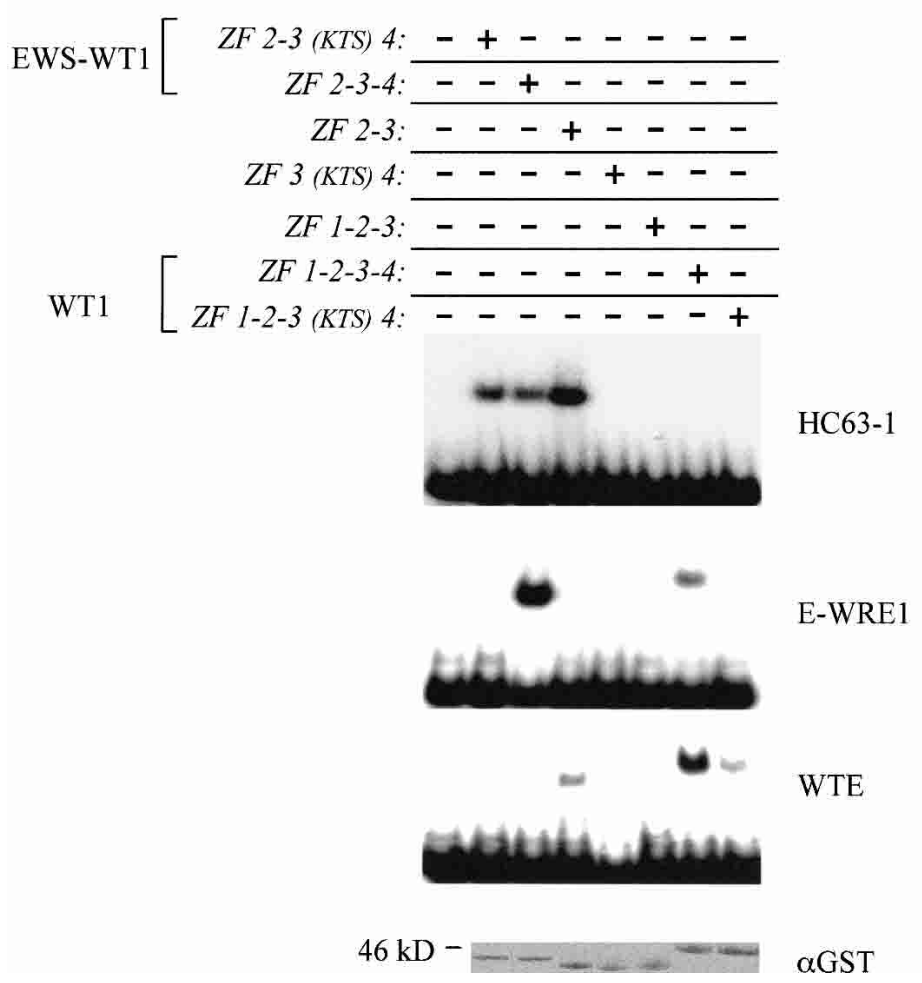

B

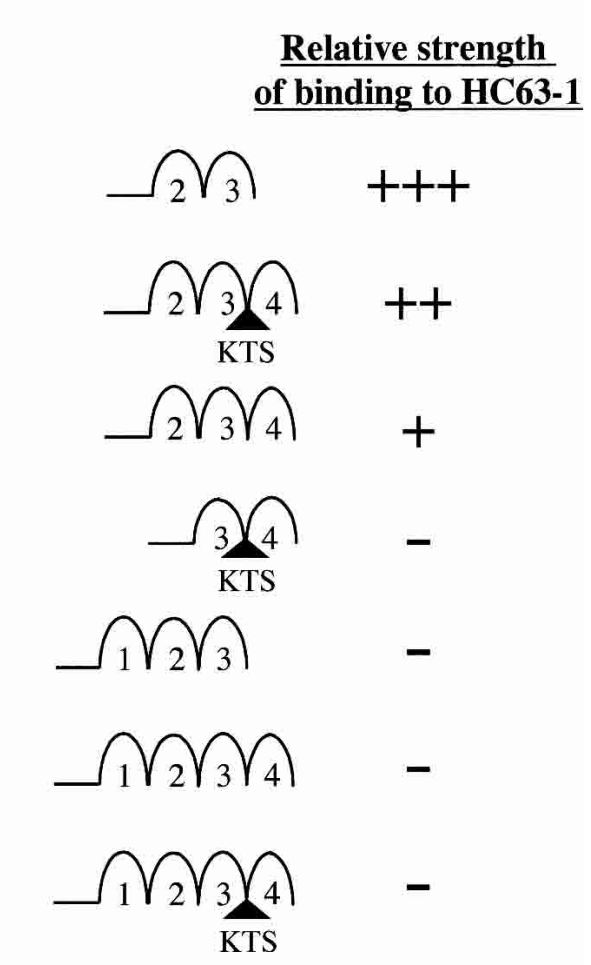

Figure 5. Characterization of zinc finger binding to E(KTS)RE. (A) EMSA analysis of combinations of WT1-derived zinc finger proteins. Binding is shown by using HC63-1, which contains the EWS-WT1(+KTS) binding sequence E(KTS)RE, and using consensus sequences previously identified for EWS-WT1(-KTS) (called E-WRE1) or for WT1(-KTS) (called WTE). A loading control for expression of zinc finger proteins is shown by using Western blotting with anti-GST antibody $(\alpha \mathrm{GST})$. (B) Relative binding affinity of combinations of WT1-derived zinc finger proteins for the E(KTS)RE sequence. Results from multiple EMSA experiments using HC63-1 probe are represented schematically.

stead of a fixed nucleotide recognition code for each zinc finger in isolation, recent studies have shown that neighboring zinc fingers can act synergistically to bind DNA. Thus, a change in the binding capability of one zinc finger can potentially affect the sequence specificity of the protein as a whole (Isalan et al. 1997, 1998; Elrod-Erickson et al. 1998). The effect of the (KTS) insertion between WT1 zinc fingers 3 and 4 is therefore likely to be complex. By altering the spacing between zinc fingers 3 and 4 , it may shift zinc finger 4 away from the major groove, and its effects on the flanking zinc fingers 3 and 4 may be associated with altered DNA binding by the entire zinc finger domain.

Our results indicate that in vivo recognition of the novel 5'-GGAGG(A/G)-3' consensus by EWS-WT1(+KTS) is mediated primarily by zinc fingers 2 and 3 . We note, however, that the 5'-GGAGG(A/G)-3' consensus occurs $\sim 80$ times in the 70-kb genomic sequence between HC63 and the LRRC15 transcriptional start site; yet, transcriptional activation appears restricted to the E(KTS)RE sites within the HC63 genomic fragment. Specific in vivo binding is therefore likely to be modulated by additional DNA-binding factors, flanking sequences, as well as a favorable chromatin context defining accessible sites. In vitro zinc finger studies have suggested that high-affinity and high-specificity DNA binding requires at least three zinc fingers (Wang and Pabo 1999; Joung et al. 2000). However, flanking zinc fingers 2 and 3 with additional WT1-derived zinc fingers within the correct phase for binding to the major groove of DNA abrogates their binding to $\mathrm{E}(\mathrm{KTS}) \mathrm{RE}$. For instance, addition of zinc finger 1 , as in WT1(+KTS), or zinc finger 4 , as in EWSWT1(-KTS), reduces binding affinity. Stabilization of DNA binding by zinc fingers 2 and 3 might therefore be mediated by an alternative mechanism, such as zinc finger-protein interactions. It is likely that the insertion of KTS shifts zinc finger 4 out of register, preventing its contact with DNA but making it accessible for a protein-protein stabilizing interaction. According to this model, the loss of zinc finger 1 resulting from the EWSWT1 translocation, together with the displacement of zinc finger 4 by the KTS insertion, would allow for highaffinity binding to a unique DNA recognition element and transcriptional activation of novel genes.

Given these considerations, it is not surprising that the DNA recognition sequence derived for each finger within the setting of the parental WT1 protein is not predictive of the sequence recognized by EWSWT1(+KTS). Our approach in first identifying an endogenous target gene, and then searching for a responsive 
A

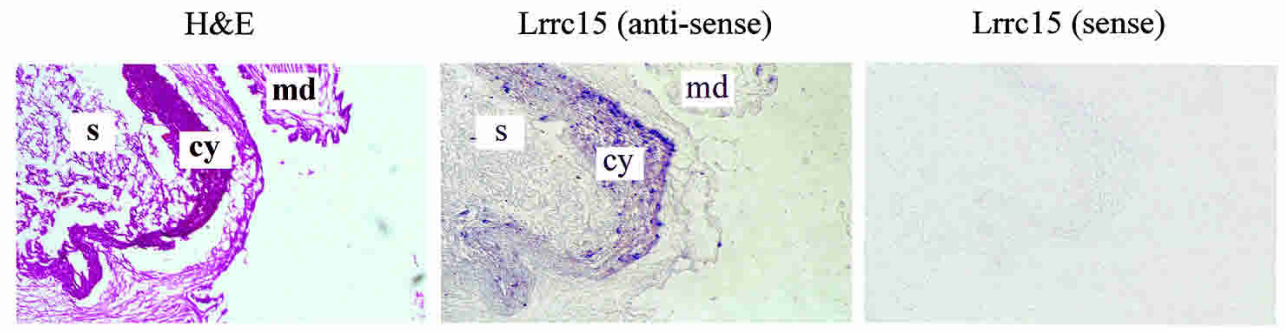

B

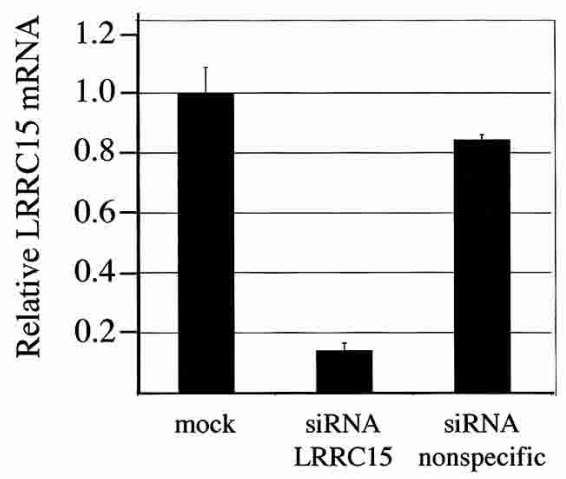

Transwell - Matrigel invasion

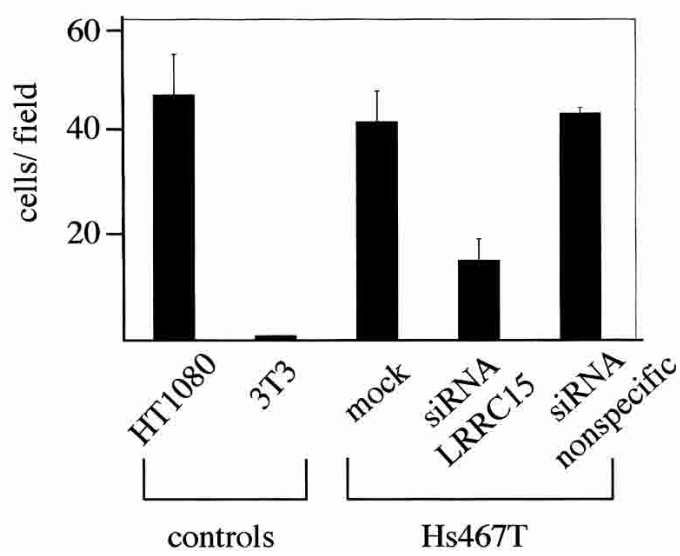

Transwell - plastic migration

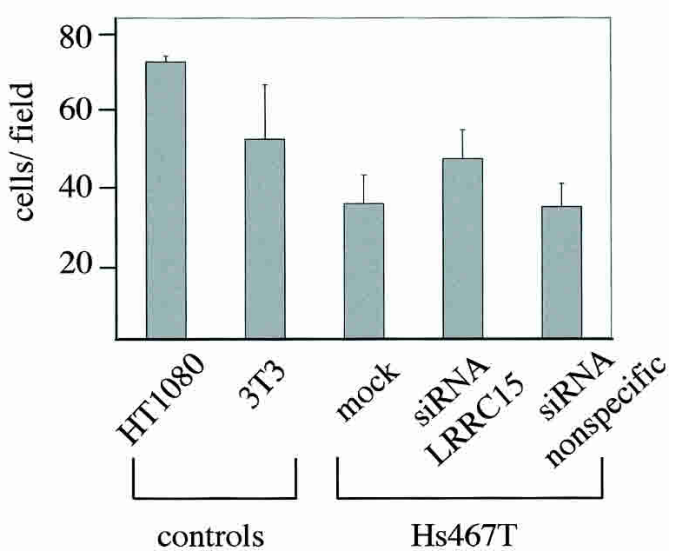

Figure 6. Role of LRRC15 in cellular invasion. (A) RNA in situ hybridization analysis of Lrrc15 in mouse placenta (magnification, 80x). Adjacent section is stained with H\&E showing cytotrophoblast layer (cy), stroma (s), and maternal decidua (md). Lrrc15 expression is restricted to cytotrophoblast cells. No staining is observed with a control (Lrrc15 sense) probe. $(B$, top) Effect of $L R R C 15$ expression on matrigel invasion by Hs467T breast cancer cells. Quantitative real-time RT-PCR (TaqMan) analysis of LRRC15 transcript from Hs467T cells, $72 \mathrm{~h}$ after treatment with specific siRNA duplexes, nonspecific duplexes, or untreated (mock). The expression of GAPDH was used to normalize for variances in input cDNA. (Bottom) Results of transwell migration assays are shown for matrigel-coated plates (correlated with cellular invasion) or for uncoated plastic (correlated with cellular migration). Hs467T cells treated with LRRC15 siRNA or nonspecific siRNA, or mock-treated controls are compared with the highly invasive HT1080 cells and the noninvasive NIH 3 T3 cells. Standard deviations are derived from three independent experiments.

regulatory sequence, was therefore unbiased and succeeded in defining the novel E(KTS)RE consensus sequence. A similar strategy may be important in determining whether the parental tumor suppressor, WT1 $(+\mathrm{KTS})$ is capable of direct DNA binding and regulation of gene expression. WT1(+KTS) and EWSWT1(+KTS) differ in their subnuclear localization. Pres- ence of WT1(+KTS) within nuclear bodies containing snRNPs and its coimmunoprecipitation with the splicing factor U2AF65 have implied a role in some aspect of premRNA processing (Larsson et al. 1995; Davies et al. 1998). Nonetheless, our results raise the possibility that WT1(+KTS) may also bind a specific DNA sequence defined by zinc fingers 1-3. Previous studies have searched 
for WT1(+KTS) DNA-binding sites, but no specific site has been confirmed to date (Bickmore et al. 1992).

The identification of a transcriptional target for EWSWT1(+KTS) also provides new insight into the transforming properties of this tumor-specific translocation product. LRRC15 encodes an $\mathrm{N}$-terminal transmembrane domain, 15 LRRs, and a short C-terminal cytoplasmic tail. LRR-containing cell surface proteins have diverse functions, with many linked to a role in cell adhesion or signaling, including the family member LGI1, which is inactivated during malignant progression in brain tumors (Chernova et al. 1998). The LRR superfamily member that is closest in amino acid sequence to $L R R C 15$ is GP5. These two genes share the same genomic structure and are adjacent to each other, consistent with a tandem gene duplication event. GP5 encodes a subunit of the GP1b-V-IX receptor that binds von Willebrand factor and is important in platelet aggregation (Roth et al. 1996; Gurney et al. 2002), and it may act to negatively regulate the response of the activated receptor (Ramakrishnan et al. 1999). We have shown that $L R R C 15$ also encodes a transmembrane glycoprotein, expressed at the leading edge of migrating cells. Although functional analyses suggest that LRRC15 is likely to be involved in cellular invasion, further work will be required to identify potential ligands or associated cofactors.

The normal expression pattern of $L R R C 15$ appears to be restricted to invasive cells in the placental cytotrophoblast layer. As such, the induction of LRRC15 by EWS-WT1(+KTS) may represent the misappropriation of a physiological invasion mechanism by an oncogenic chimera. It is of interest that the rat ortholog, $L i b$, was identified in the highly invasive C6 glioblastoma cell line, where its expression is induced by addition of cytokines or $\beta$-amyloid (Satoh et al. 2002). In vitro, we have demonstrated that LRRC15 contributes to the invasion of breast cancer cells through matrigel, a reconstituted basement membrane matrix derived from mouse sarcoma cells. Matrigel invasion serves as a useful in vitro correlate of tumor invasion, correlated with the ability of cancer cells to penetrate reactive stroma and surrounding tissues (Park et al. 2000; Liotta and Kohn 2001; Tuxhorn et al. 2001, 2002). DSRCT is notable for the presence of desmoplastic stroma and a high degree of invasiveness, raising the possibility that LRRC15 may play a significant role in tumorigenesis. Approaches to inhibition of LRRC15 function may have therapeutic potential in this refractory human cancer.

\section{Materials and methods}

\section{Generation of cell lines and cDNA subtraction}

Full-length EWS-WT1(+KTS) cDNA was generated by using RT-PCR from a primary DSRCT, confirmed by nucleotide sequencing, and fused to a C-terminal hemagglutinin (HA) epitope into the pCDNA3 vector (Invitrogen). U2OS cells with tetracycline-repressible EWS-WT1(+KTS) expression were generated and maintained in $1 \mu \mathrm{g} / \mathrm{mL}$ tetracycline as described previously (Englert et al. 1995; Lee et al. 1997). UED5, a clone with tightly regulated, 100- to 200-fold inducible expression of EWSWT1(+KTS) was used for analysis. Immunofluorescence microscopy was performed as described (Lee et al. 1997). Tetracycline was withdrawn for $12 \mathrm{~h}$; total RNA was isolated with RNA STAT60 (Tel-Test); and poly(A) ${ }^{+}$-selected RNA was obtained by using oligo(dT) resin (Invitrogen). cDNA subtraction was performed by using the PCR-select kit (Clontech). A cDNA-subtracted plasmid library was generated by subcloning into pCR2.1 (Invitrogen) and predicted target cDNAs were confirmed using Northern blotting. Frozen mouse tissue specimens were obtained from the Dana-Farber/Harvard Cancer Center Pathology Core Facility and frozen tumor specimens of DSRCT from either the same source or the Memorial Sloan-Kettering tumor bank.

\section{LRRC15 cloning and characterization}

To clone full-length cDNAs corresponding to subtraction products, poly $(\mathrm{A})^{+}$-selected RNA from U2OS cells expressing EWSWT1 $(+\mathrm{KTS})$ was used to generate a cDNA library in $\lambda$ screen-1 (Novagen). Approximately $5 \times 10^{5}$ pfu was screened by using a subtracted fragment as a probe by standard methods. The additional nucleotide sequence obtained was used to interrogate the NCBI database in which an exact match to a genomic contig (accession no. AC025389) is shown. Bioinformatics programs (http://genes.mit.edu and http://compbio.ornl.gov/Grail) were used to find an ORF of $1741 \mathrm{bp}$ within a 6-kb transcript in which the subtracted cDNA mapped to the 3' UTR. To verify that the predicted transcript was full length, poly $(\mathrm{A})^{+}$-selected RNA from U2OS cells expressing EWS-WT1(+KTS) was also used to perform 5 '-rapid amplification of cDNA ends (RACE) reactions (Clontech). Three primers were used: 4R (5'-CAGGGAATTC CCAAAGAGAGTAAGACGG-3'), 3R (5'-GTGCGTGTTGAG GATCTGCAGGCTCATGG-3'), 12R (5'-CTGCCTGAATGAC TACAGTGGAAGCAGCTC-3'). Five independent clones were sequenced for each resulting product.

The full-length $L R R C 15$ ORF was cloned, along with a 3' HA tag into the CMV-driven pCDNA3 plasmid (Invitrogen). Stable cell lines were prepared by cotransfecting $L R R C 15$ expression constructs with the selection plasmid pBABE puro, followed by selection using $1 \mu \mathrm{g} / \mathrm{mL}$ puromycin. Immunofluorescence was performed by using antibodies to the HA-epitope (16B12) to detect HA-tagged LRRC15, FITC-conjugated antimouse antibody (Jackson ImmunoResearch), and TRITC-conjugated phalloidin (Sigma). Photographs were taken by using a Zeiss Axiovert 100 $\mathrm{M}$ confocal microscope and analyzed with a Laser Scanning Microscope 510 imaging system. Combinations of oligosaccharide digesting enzymes were added to cellular extracts of HT1080 cells expressing $L R R C 15$, according to the manufacturer's instructions (Prozyme), and LRRC15 protein was visualized by SDS-PAGE and Western blotting.

\section{LRRC15 promoter constructs and luciferase reporter assays}

To clone sequences upstream of the LRRC15 ORF, the human BAC DNA pools release IV (Research Genetics) was screened by PCR with primers LRRC15.F (5'-GAATAGTTTGTCCCTCT CATGGGAATTGGG-3') and LRRC15.R (5'-GGTGAGAACA ATCTCTCCTTAAGAG-3'), and a clone (573k19) was identified which contained LRRC15 sequence. A plasmid library was generated from this bacterial artificial chromosome (BAC) DNA digested with either EcoRI, BgIII, or HindIII by subcloning into the promoter-less luciferase vector pGL3 (Promega). Pools were 
screened for luciferase activity, and candidates were rescreened as individual clones. Substitutions were introduced by PCR to change the guanines at positions 1,2 , and 4 of E(KTS)RE1 to adenines, and the guanines at positions 1, 2, and 4 of E(KTS)RE2 to adenines. For luciferase reporter assays, $1 \mu \mathrm{g}$ of CMV-driven expression constructs or empty vector was cotransfected with $0.2 \mu \mathrm{g}$ of the promoter reporter into U2OS cells by using the calcium DNA precipitation method. Equal amounts of CMVdriven constructs were transfected in each experiment, and cotransfection of a Renilla luciferase reporter $(20 \mathrm{ng})$ was used to allow standardization for transfection efficiency. All experiments were performed in triplicate.

\section{EMSAs and ChIP}

Given the insolubility of full-length WT1 protein, the zinc finger domains of EWS-WT1(+KTS) and EWS-WT1(-KTS) were cloned into the pGEX3X GST-expression vector (Pharmacia) and expressed in Escherichia coli BL21(DE3). Deletion mutant zinc finger proteins were also generated containing zinc fingers 2 and 3 , zinc fingers 3 and 4 with the KTS alternative splice, and zinc fingers 1, 2, and 3. For mutational analysis of the EWSWT1(+KTS)-binding site, oligonucleotides containing single base pair substitutions within the E(KTS)RE were annealed, subcloned, and verified by nucleotide sequencing. End-labeled probes $(20,000 \mathrm{cpm})$ were incubated with $200 \mathrm{ng}$ of GST-WT1 protein in binding buffer as described (Palmer et al. 2002). After incubation for $30 \mathrm{~min}$ at $4^{\circ} \mathrm{C}$, binding reactions were electrophoresed on a $5 \%$ polyacrylamide gel in $0.5 \times$ TBE buffer for $2 \mathrm{~h}$ at $180 \mathrm{~V}$. For competition experiments, 100 -fold molar excess of unlabeled annealed oligonucleotides were added to $200 \mathrm{ng}$ of GST-WT1 in binding buffer. Competitor DNA was incubated for $10 \mathrm{~min}$ at room temperature prior to addition of labeled probe, followed by incubation for an additional $20 \mathrm{~min}$ at $4^{\circ} \mathrm{C}$. ChIP was performed as described (Palmer et al. 2002). The following primer sets were used: HC63 nucleotides 95549-95691 of AC025389; $\beta$-actin, nucleotides 824-1103 of E00829. Coamplification of $\beta$-actin within a multiplex PCR reaction served as an internal control for enrichment of HC63 sequences.

RNA in situ hybridization, siRNA knockdown, and in vitro invasion assay

RNA in situ hybridization was performed as described (Morgan et al. 1998; Palmer et al. 2002). SP6 and T7 flanked PCR templates were used to generate digoxigenin-labeled riboprobes (Roche Molecular Biochemicals). Probes were generated from LRRC15, nucleotides 148810-149279 of AC025389 and Lrrc15, nucleotides 1330-1822 of XM_148440. For in vitro invasion assays, Hs467T cells (ATCC) were grown in F-12/DMEM supplemented with $20 \%$ FBS at $37^{\circ} \mathrm{C}$ and $5 \% \mathrm{CO}_{2}$. Cells were seeded at $1 \times 10^{5}$ and transfected by using Oligofectamine reagent (Invitrogen) with either a LRRC15 siRNA duplex (5'-AACACG CACAUCACUGAACUC-3'), a control duplex (5'-AAGUC GUUGGGGAUGGAGUGC-3'), or mock transfection. After 72 $\mathrm{h}$, cells were trypsinized, counted, and resuspended in serumfree DMEM at a density of $5 \times 10^{4}$ cells $/ \mathrm{mL}$. RNA was isolated from cells, and quantitative real-time RT-PCR (TaqMan) was performed (Heid et al. 1996) by using the relative standard curve method with primers for $L R R C 15$ (F, 5'-CAGATGTTAGATG TATCCTAGCTTTTAGCTA-3'; R, 5'-CCCACCACCGCAGA TTCAGTT-3'; TaqMan probe, 5'-VIC-AAAGATTCAGCCCC CAGATCCCACA-TAMRA-3') and for GAPDH (F, 5'-GGTG GTCTCCTCTGACTTCAACA-3'; R, 5'-GTGGTCGTTGAGG GCAATG-3'; TaqMan probe, 5'-VIC-ACCCACTCCTCCAC CTTTGACGCTG-TAMRA-3'). The expression of GAPDH was used to normalize for variances in input cDNA. Cell migration and invasion were examined by using in vitro cell migration (plastic alone) and invasion (matrigel-coated) 24-well chambers with $8.0 \mu \mathrm{m}$ pores (Biocoat, Becton Dickinson); $0.5 \mathrm{~mL}$ aliquots of cell suspension were added to the top chamber, and DMEM supplemented with $10 \%$ FBS was added to the lower chamber. After $20 \mathrm{~h}$, the top side of the insert membrane was scrubbed free of cells by using a cotton swab and PBS washes, and the bottom side was stained by using $0.1 \%$ crystal violet stain (Sigma). Inserts were cut out of the chamber, placed onto glass slides, and overlayed with coverslips and Vectashield mountant containing DAPI (Vector Laboratories). Fluorescence microscopy was used to visualize cells and nuclei, and the number of cells in 10 randomly selected fields were counted for each membrane disc.

\section{Accession numbers}

LRRC15 mRNA sequence is available in the Third Party Annotation section of the DDBJ/EMBL/GenBank databases under the accession number TPA: BK001325.

\section{Acknowledgments}

We wish to dedicate this article to the memory of Bradley Kirkpatrick. We thank W. Cohen for tissue sectioning, Dr. Daphne Bell for providing cancer cell line reagents, Y. Ow and members of the Haber lab for helpful discussions, and Dr. Keith Joung for critical review of the manuscript. This work was supported by National Cancer Institute grant CA90627 (D.A.H. and W.L.G.) and the Kirkpatrick Memorial Fund.

The publication costs of this article were defrayed in part by payment of page charges. This article must therefore be hereby marked "advertisement" in accordance with 18 USC section 1734 solely to indicate this fact.

\section{References}

Albini, A., Iwamoto, Y., Kleinman, H.K., Martin, G.R., Aaronson, S.A., Kozlowski, J.M., and McEwan, R.N. 1987. A rapid in vitro assay for quantitating the invasive potential of tumor cells. Cancer Res. 47: 3239-3245.

Backer, A., Mount, S.L., Zarka, M.A., Trask, C.E., Allen, E.F., Gerald, W.L., Sanders, D.A., and Weaver, D.L. 1998. Desmoplastic small round cell tumour of unknown primary origin with lymph node and lung metastases: Histological, cytological, ultrastructural, cytogenetic and molecular findings. Virchows Arch. 432: 135-141.

Barbaux, S., Niaudet, P., Gubler, M.C., Grunfeld, J.P., Jaubert, F., Kuttenn, F., Fekete, C.N., Souleyreau-Therville, N., Thibaud, E., Fellous, M., et al. 1997. Donor splice-site mutations in WT1 are responsible for Frasier syndrome. Nat. Genet. 17: 467-470.

Bertolotti, A., Melot, T., Acker, J., Vigneron, M., Delattre, O., and Tora. L. 1998. EWS, but not EWS-FLI-1, is associated with both TFIID and RNA polymerase II: Interactions between two members of the TET family, EWS and hTAFII68, and subunits of TFIID and RNA polymerase II complexes. Mol. Cell. Biol. 18: 1489-1497.

Bickmore, W.A., Oghene, K., Little, M.H., Seawright, A., van Heyningen, V., and Hastie, N.D. 1992. Modulation of DNA binding specificity by alternative splicing of the Wilms tumor wt1 gene transcript. Science 257: 235-237.

Carter, D., Chakalova, L., Osborne C.S., Dai, Y., and Fraser, P. 2002. Long-range chromatin regulatory interactions in vivo. 
Nat. Genet. 32: 623-626.

Chernova, O.B., Somerville, R.P., and Cowell, J.K. 1998. A novel gene, LGI1, from 10q24 is rearranged and downregulated in malignant brain tumors. Oncogene 17: 2873-2881.

Cummings, O.W., Ulbright, T.M., Young, R.H., Del Tos, A.P., Fletcher, C.D., and Hull, M.T. 1997. Desmoplastic small round cell tumors of the paratesticular region: A report of six cases. Am. J. Surg. Pathol. 21: 219-225.

Davies, R.C., Calvio, C., Bratt, E., Larsson, S.H., Lamond, A.I., and Hastie, N.D. 1998. WT1 interacts with the splicing factor U2AF65 in an isoform-dependent manner and can be incorporated into spliceosomes. Genes \& Dev. 12: 32173225.

de Alava, E. and Gerald, W.L. 2000. Molecular biology of the Ewing's sarcoma/primitive neuroectodermal tumor family. J. Clin. Oncol. 18: 204-213.

Elrod-Erickson, M., Benson, T.E., and Pabo, C.O. 1998. Highresolution structures of variant Zif268-DNA complexes: Implications for understanding zinc finger-DNA recognition. Structure 6: 451-464.

Englert, C., Hou, X., Maheswaran, S., Bennett, P., Ngwu, C., Re, G.G., Garvin, A.J., Rosner, M.R., and Haber, D.A. 1995. WT1 suppresses synthesis of the epidermal growth factor receptor and induces apoptosis. EMBO J. 14: 4662-4675.

Finkeltov, I., Kuhn, S., Glaser, T., Idelman, G., Wright, J.J., Roberts, C.T., and Werner, H. 2002. Transcriptional regulation of IGF-I receptor gene expression by novel isoforms of the EWS-WT1 fusion protein. Oncogene 21: 1890-1898.

Gerald, W.L., Miller, H.K., Battifora, H., Miettinen, M., Silva, E.G., and Rosai, J. 1991. Intra-abdominal desmoplastic small round-cell tumor: Report of 19 cases of a distinctive type of high-grade polyphenotypic malignancy affecting young individuals. Am. J. Surg. Pathol. 15: 499-513.

Gerald, W.L., Rosai, J., and Ladanyi, M. 1995. Characterization of the genomic breakpoint and chimeric transcripts in the EWS-WT1 gene fusion of desmoplastic small round cell tumor. Proc. Natl. Acad. Sci. 92: 1028-1032.

Gurney, D., Lip, G.Y., and Blann, A.D. 2002. A reliable plasma marker of platelet activation: Does it exist? Am. I. Hematol. 70: 139-144.

Haber, D.A., Park, S., Maheswaran, S., Englert, C., Re, G.G., Hazen-Martin, D.J., Sens, D.A., and Garvin, A.J. 1993. WT1mediated growth suppression of Wilms tumor cells expressing a WT1 splicing variant. Science 262: 2057-2059.

Hammes, A., Guo, J.K., Lutsch, G., Leheste, J.R., Landrock, D., Ziegler, U., Gubler, M.C., and Schedl, A. 2001. Two splice variants of the Wilms' tumor 1 gene have distinct functions during sex determination and nephron formation. Cell 106: 319-329.

Heid, C.A., Stevens, J., Livak, K.J., and Williams, P.M. 1996. Real time quantitative PCR. Genome Res. 6: 986-994.

Herzer, U., Crocoll, A., Barton, D., Howells, N., and Englert, C. 1999. The Wilms tumor suppressor gene wt1 is required for development of the spleen. Curr. Biol. 9: 837-840.

Isalan, M., Choo, Y., and Klug, A. 1997. Synergy between adjacent zinc fingers in sequence-specific DNA recognition. Proc. Natl. Acad. Sci. 94: 5617-5621.

Isalan, M., Klug, A., and Choo, Y. 1998. Comprehensive DNA recognition through concerted interactions from adjacent zinc fingers. Biochemistry 37: 12026-12033.

Joung, J.K., Ramm, E.I., and Pabo, C.O. 2000. A bacterial twohybrid selection system for studying protein-DNA and protein-protein interactions. Proc. Natl. Acad. Sci. 97: 73827387.

Karnieli, E., Werner, H., Rauscher, F.J., Benjamin, L.E., and LeRoith, D. 1996. The IGF-I receptor gene promoter is a mo- lecular target for the Ewing's sarcoma-Wilms' tumor 1 fusion protein. J. Biol. Chem. 271: 19304-19309.

Kim, J., Lee, K., and Pelletier, J. 1998. The desmoplastic small round cell tumor $\mathrm{t}(11 ; 22)$ translocation produces EWS/WT1 isoforms with differing oncogenic properties. Oncogene 16: 1973-1979.

Klamt, B., Koziell, A., Poulat, F., Wieacker, P., Scambler, P., Berta, P., and Gessler, M. 1998. Frasier syndrome is caused by defective alternative splicing of WT1 leading to an altered ratio of WT1 +/-KTS splice isoforms. Hum. Mol. Genet. 7: 709-714.

Kobayashi, H., Ohi, H., Sugimura, M., Shinohara, H., Fujii, T., and Terao, T. 1992. Inhibition of in vitro ovarian cancer cell invasion by modulation of urokinase-type plasminogen activator and cathepsin B. Cancer Res. 52: 3610-3614.

Kobe, B. and Deisenhofer, J. 1994. The leucine-rich repeat: A versatile binding motif. Trends Biochem. Sci. 19: 415-421.

- 1995. Proteins with leucine-rich repeats. Curr. Opin. Struct. Biol. 5: 409-416.

Kreidberg, J.A., Sariola, H., Loring, J.M., Maeda, M., Pelletier, J., Housman, D., and Jaenisch, R. 1993. WT-1 is required for early kidney development. Cell 74: 679-691

Ladanyi, M. and Gerald, W. 1994. Fusion of the EWS and WT1 genes in the desmoplastic small round cell tumor. Cancer Res. 54: 2837-2840.

Lander, E.S., Linton, L.M., Birren, B., Nusbaum, C., Zody, M.C., Baldwin, J., Devon, K., Dewar, K., Doyle, M., FitzHugh, W., et al. 2001. Initial sequencing and analysis of the human genome. Nature 409: 860-921.

Larsson, S.H., Charlieu, J.P., Miyagawa, K., Engelkamp, D., Rassoulzadegan, M., Ross, A., Cuzin, F., van Heyningen, V., and Hastie, N.D. 1995. Subnuclear localization of WT1 in splicing or transcription factor domains is regulated by alternative splicing. Cell 81: 391-401.

Lee, S.B. and Haber, D.A. 2001. Wilms tumor and the WT1 gene. Exp. Cell. Res. 264: 74-99.

Lee, S.B., Kolquist, K.A., Nichols, K., Englert, C., Maheswaran, S., Ladanyi, M., Gerald, W.L., and Haber, D.A. 1997. The EWS-WT1 translocation product induces PDGFA in desmoplastic small round-cell tumour. Nat. Genet. 17: 309-313.

Liotta, L.A. and Kohn E.C. 2001. The microenvironment of the tumour-host interface. Nature 411: 375-379.

May, W.A., Gishizky, M.L., Lessnick, S.L., Lunsford, L.B., Lewis, B.C., Delattre, O., Zucman, J., Thomas, G., and Denny, C.T. 1993a. Ewing sarcoma 11;22 translocation produces a chimeric transcription factor that requires the DNAbinding domain encoded by FLI1 for transformation. Proc. Natl. Acad. Sci. 90: 5752-5756.

May, W.A., Lessnick, S.L., Braun, B.S., Klemsz, M., Lewis, B.C., Lunsford, L.B., Hromas, R., and Denny, C.T. 1993b. The Ewing's sarcoma EWS/FLI-1 fusion gene encodes a more potent transcriptional activator and is a more powerful transforming gene than FLI-1. Mol. Cell. Biol. 13: 7393-7398.

Morgan, B., Orkin, R., Noramly, S., and Perez, A. 1998. Stagespecific effects of sonic hedgehog expression in the epidermis. Dev. Biol. 201: 1-12.

Morrish, D.W., Dakour, J., and Li, H. 1998. Functional regulation of human trophoblast differentiation. J. Reprod. Immunol. 39: 179-195.

Palmer, R.E., Lee, S.B., Wong, J.C., Reynolds, P.A., Zhang, H., Truong, V., Oliner, J.D., Gerald, W.L., and Haber, D.A. 2002. Induction of BAIAP3 by the EWS-WT1 chimeric fusion implicates regulated exocytosis in tumorigenesis. Cancer Cell 2: 497-505.

Park, C.C., Bissell, M.J., and Barcellos-Hoff, M.H. 2000. The influence of the microenvironment on the malignant pheno- 
type. Mol. Med. Today 6: 324-329.

Pavletich, N.P. and Pabo, C.O. 1991. Zinc finger-DNA recognition: Crystal structure of a Zif268-DNA complex at $2.1 \AA$. Science 252: 809-817.

Ramakrishnan, V., Reeves, P.S., DeGuzman, F., Deshpande, U., Ministri-Madrid, K., DuBridge, R.B., and Phillips, D.R. 1999. Increased thrombin responsiveness in platelets from mice lacking glycoprotein V. Proc. Natl. Acad. Sci. 96: 1333613341.

Roth, G.J., Yagi, M., and Bastian, L.S. 1996. The platelet glycoprotein Ib-V-IX system: Regulation of gene expression. Stem Cells 14 (Suppl. 1): 188-193.

Satoh, K., Hata, M., and Yokota, H. 2002. A novel member of the leucine-rich repeat superfamily induced in rat astrocytes by $\beta$-amyloid. Biochem. Biophys. Res. Commun. 290: 756762 .

Tupler, R., Perini, G., and Green, M.R. 2001. Expressing the human genome. Nature 409: 832-833.

Tuxhorn, J.A., Ayala, G.E., and Rowley, D.R. 2001. Reactive stroma in prostate cancer progression. J. Urol. 166: 24722483.

Tuxhorn, J.A., Ayala, G.E., Smith, M.J., Smith V.C., Dang, T.D., and Rowley, D.R. 2002. Reactive stroma in human prostate cancer: Induction of myofibroblast phenotype and extracellular matrix remodeling. Clin. Canc. Res. 8: 2912-2923.

Venter, J.C., Adams, M.D., Myers, E.W., Li, P.W., Mural, R.J., Sutton, G.G., Smith, H.O., Yandell, M., Evans, C.A., Holt, R.A., et al. 2001. The sequence of the human genome. Science 291: 1304-1351.

Wagner, K.D., Wagner, N., Vidal, V.P., Schley, G., Wilhelm, D., Schedl, A., Englert, C., and Scholz, H. 2002. The Wilms' tumor gene Wt1 is required for normal development of the retina. EMBO J. 21: 1398-1405.

Wang, B.S. and Pabo, C.O. 1999. Dimerization of zinc fingers mediated by peptides evolved in vitro from random sequences. Proc. Natl. Acad. Sci. 96: 9568-9573.

Waterston, R.H., Lindblad-Toh, K., Birney, E., Rogers, J., Abril, J.F., Agarwal, P., Agarwala, R., Ainscough, R., Alexandersson, M., An, P., et al. 2002. Initial sequencing and comparative analysis of the mouse genome. Nature 420: 520-562.

Wong, J.C., Lee, S.B., Bell, M.D., Reynolds, P.A., Fiore, E., Stamenkovic, I., Truong, V., Oliner, J.D., Gerald, W.L., and Haber, D.A. 2002. Induction of the interleukin-2/15 receptor $\beta$-chain by the EWS-WT1 translocation product. Oncogene 21: 2009-2019. 


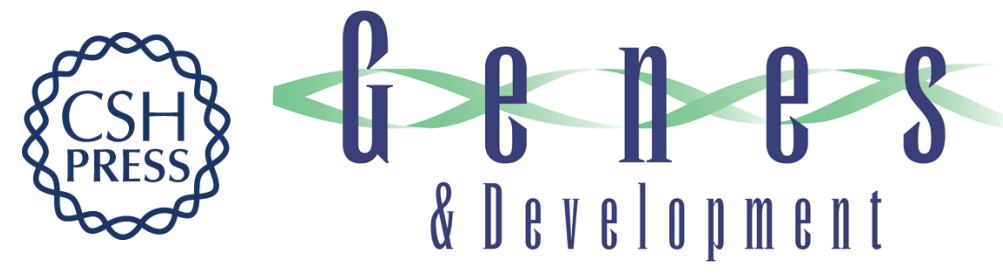

\section{Identification of a DNA-binding site and transcriptional target for the EWS-WT1(+KTS) oncoprotein}

Paul A. Reynolds, Gromoslaw A. Smolen, Rachel E. Palmer, et al.

Genes Dev. 2003, 17:

Access the most recent version at doi:10.1101/gad.1110703

$\begin{array}{ll}\text { References } & \begin{array}{l}\text { This article cites } 53 \text { articles, } 21 \text { of which can be accessed free at: } \\ \text { http://genesdev.cshlp.org/content/17/17/2094.full.html\#ref-list-1 }\end{array}\end{array}$

License

Email Alerting

Receive free email alerts when new articles cite this article - sign up in the box at the top

Service right corner of the article or click here.

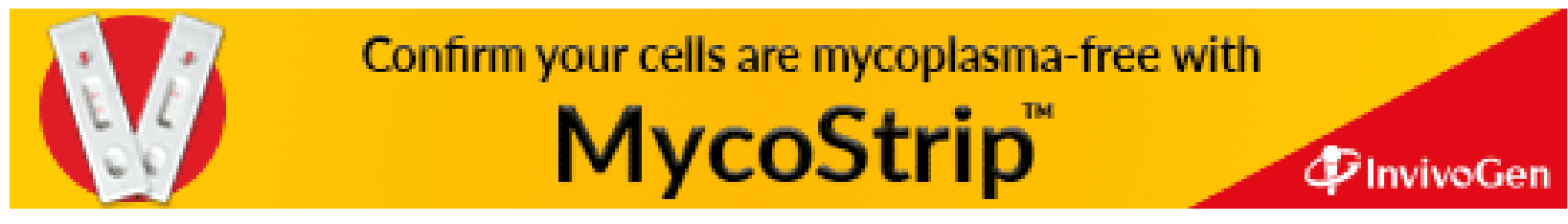

